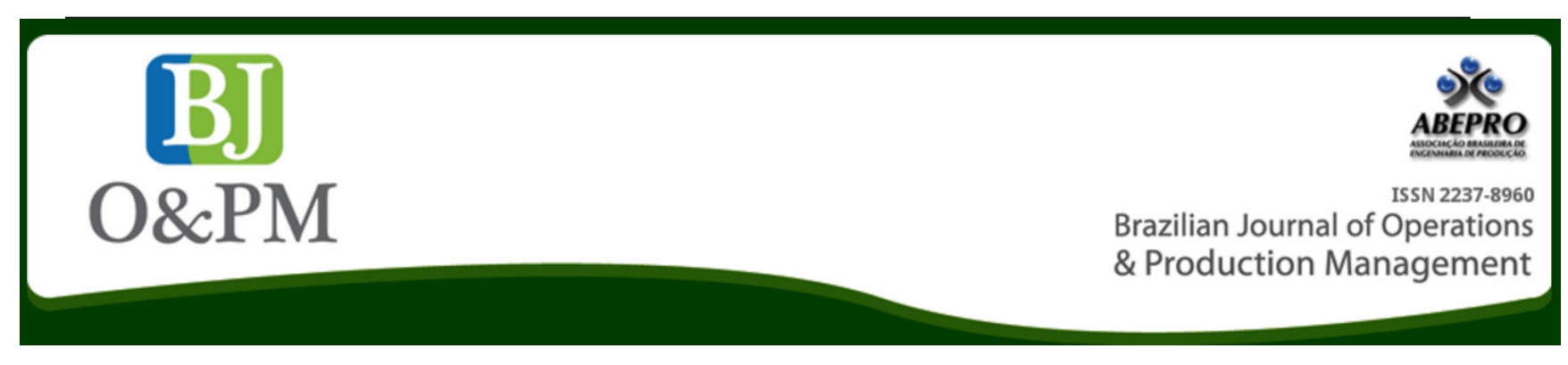

\title{
PROPOSALS FOR ENVIRONMENTAL IMPROVEMENT OVER THE WOODEN PANELS PRODUCTIVE PROCESS UNDER A BRAZILIAN CONDITION, FOCUSING ON THE IMPACTS FOR THE HUMAN TOXICITY CATEGORY
}

\author{
Rodrigo Salvadora; Lucas Xavier de Oliveira ${ }^{a}$; Antonio Carlos de Francisco ${ }^{\text {; }}$ Cassiano Moro Piekarski ${ }^{\mathrm{a}}$ \\ ${ }^{\text {a }}$ Federal University of Technology (UTFPR) - Ponta Grossa, PR, Brazil
}

\begin{abstract}
The Brazilian wooden panel industry has been growing over the last decades, what increases the concerns with its productive characteristics and the consequences of the practices adopted. The objective of this study is to present a discussion regarding the importance of the assessment on the environmental profile of wooden panels produced in Brazil, prioritizing the panels with bigger prominence in the segment, due to their potential damage to the human health resulting from their production processes and use. This paper focuses on the human toxicity category because this is one impact category on which the panels' characteristics contribute to since the conception of raw materials even after its expedition and posterior use. In light of that, a set of potential improvements are proposed in order to reduce the environmental loads of the processes here approached, considering the hotspots identified in studies under the Brazilian conditions. For the human toxicity category, the hotspots were: consume of the binding agent, consume of electrical energy, consume of wood chips and transportation.
\end{abstract}

Keywords: wood panel, Ica, environmental impact.

\section{INTRODUCTION}

The increasing concern about the natural environment management in a worldwide panorama, the use of natural resources and the care with the nature stimulate the assessment on the productive systems performance and on the development of actions in the search for solutions and improvements in the sustainable context.

Moreover, increasing segments need this attention even more. Furniture and the interiors' architecture industries that use wooden panels on a large scale are examples of these segments. For their part, these panels are there in a wide variety and possess a range of applications, in accordance with their physical-mechanical and aesthetic characteristics.

Brazil is the sixth wooden panels largest producer in the world (Biazus et al., 2010), and $78.9 \%$ of the furniture industry are represented by wooden-based furniture (Leão et Naveiro, 2009). With an increasing trend in the wooden panels sector, pressure on the organizations (Silva et al., 2013), and the real need to attempt to the safety aspect and sustainability of the productive processes, the importance of assessment on the impacts caused by such processes is perceived and the search for solutions for the prevention, eradication or easing of the real and potential impacts already found.

In view of the above, this work aims to present a discussion regarding the importance of the assessment on the environment participation of wooden panels produced in Brazil, prioritizing the panels with bigger prominence in the segment, for their potential damage to the human health resulting from the production process and the use of the same ones. For such, the use of a tool widely used with the intention of environment analysis is suggested, the Life Cycle Assessment (LCA) (PIEKARSKI et al., 2014; BOCKEN et al., 2012).

The current concern about a sustainable production urges the research with respect to the search for less impact alternatives for the means of production, considering the triple bottom line. This discussion highlights the wooden panel production's social and environmental aspects, through the potential damage to the human health, either to consumers or workers passively exposed during the production process. Moreover, considering the aspect of inherent social responsibility related to the productive practices, the environment and social damages due to 
production processes are in charge of the company that practices and manages it (Demajorovic et Silva, 2010). Furthermore, a gap related to studies about wooden panels life cycle made in Brazil and their environmental profiles is visible.

Thus, soon after the methodology (2) used in this study is presented, a brief background explanation regarding the wooden panels in Brazil (3), the LCA tool (4) is addressed, its role on this environment context and its usage in the assessment on wooden panel environmental profiles. Further, a discussion regarding the assessment on environmental profile of the related panels is drawn, wherein improvement potential points are addressed (5). Finally, Final Considerations of the study (6) and References used herein are presented.

\section{METHODS}

For the accomplishment of this study, a survey about wooden panel theoretical reference was taken, primarily Medium Density Fibreboard (MDF) and Medium Density Particleboard (MDP) panels and their productive characteristics, as well as the Life Cycle Assessment (LCA) and its role on the natural environment context. Thereafter, the LCAs carried through for MDF and MDP panels in the Brazilian productive scene and their results were considered, in order to propose improvements suggestions to the environmental profiles of these panels under the Human Toxicity (HT) impacts category perspective, using the Pareto chart as tool of prioritization about aspects to be dealt with.

\section{WOODEN PANELS}

Brazil is the sixth worldwide greatest wooden panel producer (Biazus et al., 2010) and the production has increased in recent years (FAOSTAT, 2015a). With the increasing application in the civil construction sector, furniture and decoration industry, the panels are shown as an alternative to the traditional sawed wooden use. This fact highlights the importance of a conscious management of the productive systems. Medium Density Fibreboard (MDF), Medium Density Particleboard (MDP), Oriented Strand Board (OSB) and Hard Board (HB), are among the main wooden panels in the Brazilian market, the two first being the ones with the largest representation for presenting a larger production and consumption.

\subsection{Medium Density Fibreboard (MDF)}

The MDF panel is comprised of a sheet manufactured from wooden fibers, which are agglutinated with the synthetic resin aid, and pressure and temperature joint action. Wood chips are obtained from the woodcut that are crushed and then clamped (Rosa et al., 2007).

MDF is a non-structural panel developed in the 1970 decade, which throughout the years evolved to a high engineering product (Wilson, 2010). It presents itself as very simply and easy to machine and it has good dimension stability, also, does not possess wood knot as the natural wood (Rosa et al., 2007). The MDF possess a great application in some segments and it is possible to observe that its production has increased since 1997 (Biazus et al., 2010) (see Figure 1). This fact justifies the need for caution regarding the impacts that the product can generate, either by the product as a whole, or by specific components.

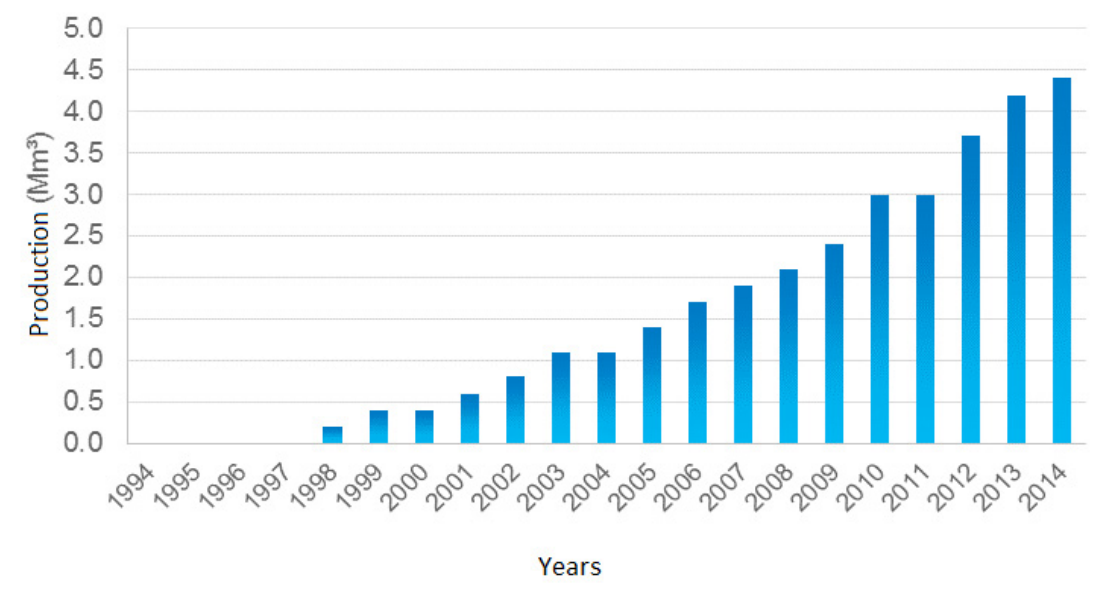

Figure 1 - Brazilian MDF production

Source: FAOSTAT (2015a) 
The MDF production started in Brazil in 1997, and since then it has been growing significantly. In addition, most of the production is consumed in the country, not having the exportation as objective.

\subsection{Medium Density Particleboard (MDP)}

The particleboard is one of the most important products of the wood according to Rivela et al. (2006). Beyond using wooden residues, the finished items have been used in a range of industries. Furthermore, the MDP is one of the most represented particleboard in the wooden board industry in Brazil (Silva et al., 2013), showing great and increasing consumption, as it can be verified in Figure 2, below.

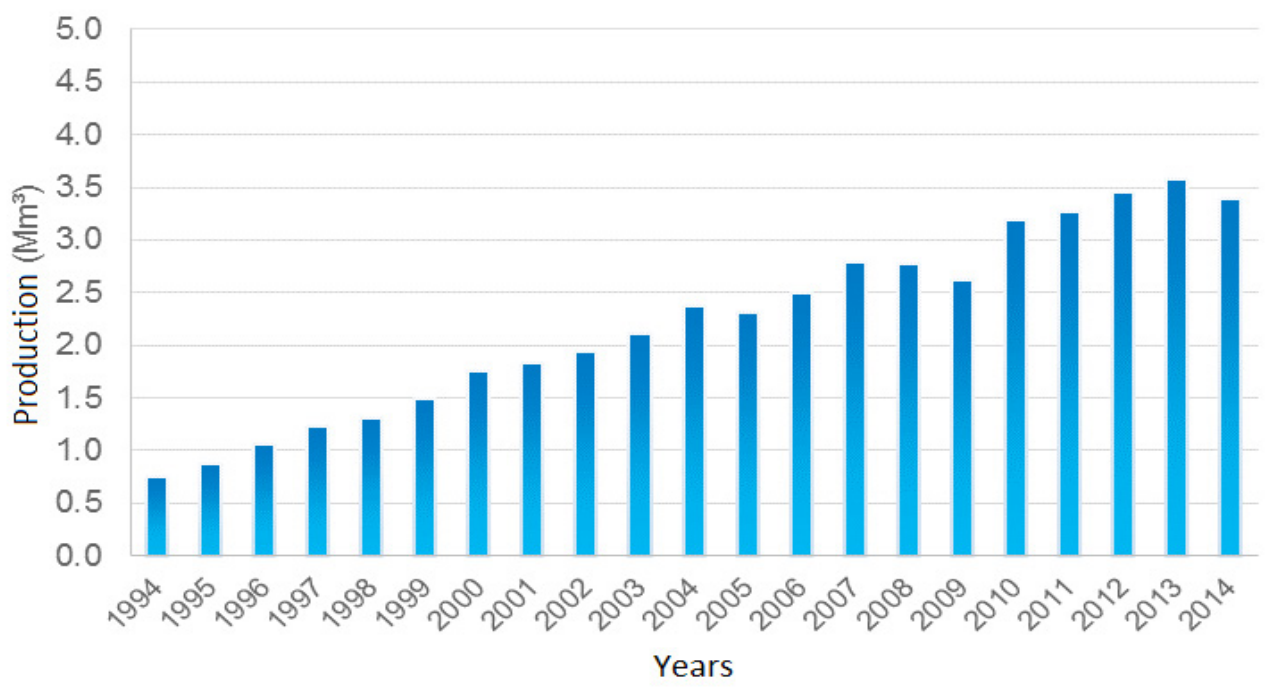

Figure 2 -Brazilian MDP production

Source: FAOSTAT (2015a)

Note: the data related to the Brazilian MDP production were obtained from the FAOSTAT (2015a) database, under the name of particleboard, according to Vidal et Hora (2015) many times still treated as chipboard, although the MDP board has started to substitute the known chipboard panel a few years ago.

Iritani et al. (2015) affirm that the MDP is the most consumed wood composite in the world, and it adjacently helps to justify the volume of LCA studies that this panel presents in comparison to similar ones. Even this relevance is perceived, an absence of studies about LCA with certain environment significance regarding to the MDP is noticed (Rivela et al., 2006), especially in the Brazilian scenario.

\section{LIFE CYCLE ASSESSMENT (LCA)}

The LCA is a tool of natural environment assessment that aims to identify the impacts caused by a system, either it being a product, process or service (Pehnt, 2005). An LCA study is composed by 4 interactive stages: (1) Definition of scope and target, (2) Life Cycle Inventory Analysis (3) Life Cycle Impact Assessment and (4) Life Cycle Interpretation.
Definition of scope and target (1) deals with the definition of the objectives to be reached with the realization of the study, as well as the delimitation of the system to be studied, besides the definition of the category indicators to be used in the study. Life Cycle Inventory Analysis (LCI) (2) comprises the data collection, wherein all the incoming data (raw materials, inputs used in the process, as well as water and energy) and output data from the system (finished items, coproduct, residues and emissions). At the Life Cycle Impact Assessment (LCIA) (3) stage, the classification and quantification of the impacts take place and it is possible to find the contribution of each product or process on the system global impact (Bribián et al., 2009; Curran, 1993). Finally, in the Life Cycle Interpretation (4) the conclusions concerning the study are outlined therein. It is where the necessary changes in the plan over the search for the impacts reduction on the system are put into practice (Blacksmith, 2004). The accomplishments of changes are based, as Svoboda (1995) states, regarding mainly to the identified hotspots (Molina-Murillo et Smith, 2009), being able to be characterized as an enterprising tool for green innovations and operations management of the company (Luz et al., 2015; Piekarski et al., 2013). 


\subsection{Life Cycle Assessment on the wooden panel in the Brazilian scenario}

There is a lack of studies about the wooden panel life cycle in the Brazilian scene. Although MDP, MDF, OSB and $H B$ panels are sufficiently representative in the Brazilian market, only the two first ones received enough attention in this aspect. Silva (2012) carried out a LCA study over the MDP produced in Brazil; Piekarski (2013) executed it for the MDF.

However, in the European scenario, LCAs for the OSB (Luxemburg) (Benetto et al., 2009) and HB (Spain) (GonzálezGarcía, 2011), are found among others. Nonetheless, significant discrepancies indeed can be found regarding to the Brazilian context, once the transport structures, the energy matrices and the input characteristics among other aspects can differ making exact comparisons not possible. Therefore, it is considered in the present study only wooden panels LCAs of the ones produced in Brazil.

\subsubsection{MDF Life Cycle Assessment (Piekarski, 2013)}

The MDF comes forward as one of the most promising panels in the Brazilian market, with its production presenting a vertiginous growth since its introduction in the country in 1997, as it can be observed in the Figure 1 (see 2, 1).

Piekarski (2013) made use of a cradle-to-gate approach, having in account from the acquisition of natural resources to the finished product shipping by the industrial unit. The Umberto ${ }^{\circledR}$ software v5.6 Academic was used, also the Ecoinvent database 2.2. For the impact measurements the CML (2001), EDIP (1997) and USEtox (2008) methods were used, considering 8 categories of impact, being the same ones: acidification potential, global heating, depletion of the ozone layer, depletion of abiotic resources, tropospheric ozone photochemical formation, ecotoxicity, eutrophication and toxicity in humans. Yet, this last category was divided into carcinogenic and non-carcinogenic, the assessment being carried through using as reference the USEtox 2008 method, which indicated to carcinogenic ( $40.27 \%$ of the total of the related category) the industrial production process as the main toxicological/carcinogenic. For non-carcinogenic (59, $73 \%$ from the total of the related category), the main contributor was the electric energy generation. Both results (carcinogenic and non-carcinogenic) can be seen in Figures 3 and 4 hereafter, together with the Pareto curve showing the potential of improvement yet to be reached as the actions for reduction of the impacts are taken.

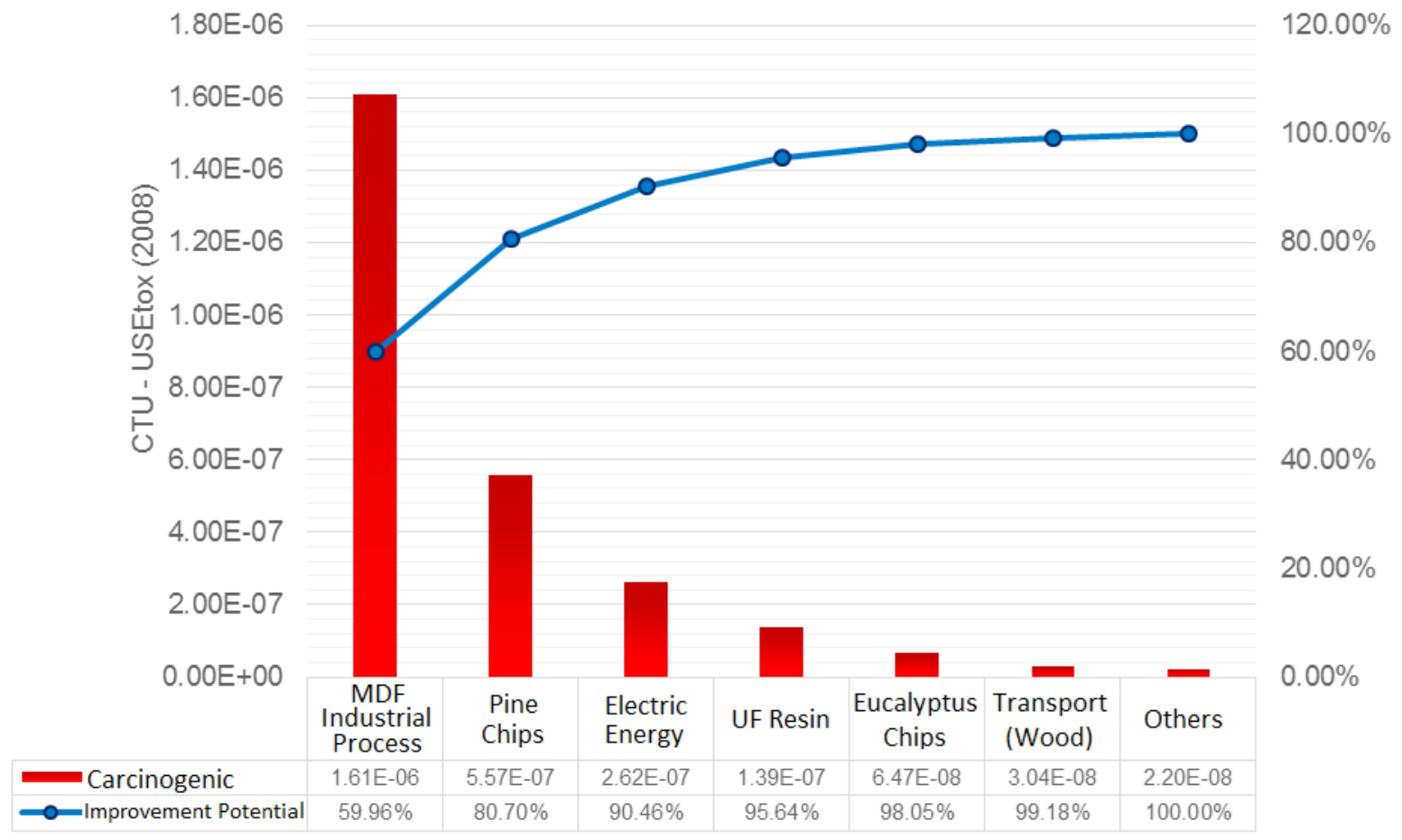

Figure 3 - Pareto chart - carcinogenic agents of the human toxicity potential category in the MDF production 
The MDF industrial process, representing $60 \%$ of the HT category carcinogenic agents, due to the strong influence on the emission of the free formaldehyde, come up as main hotspot in the search for improvements. Followed by the production of pine chips $(21 \%)$ wherein the use of toxic substances deployed in the forest handling is the main impact source.

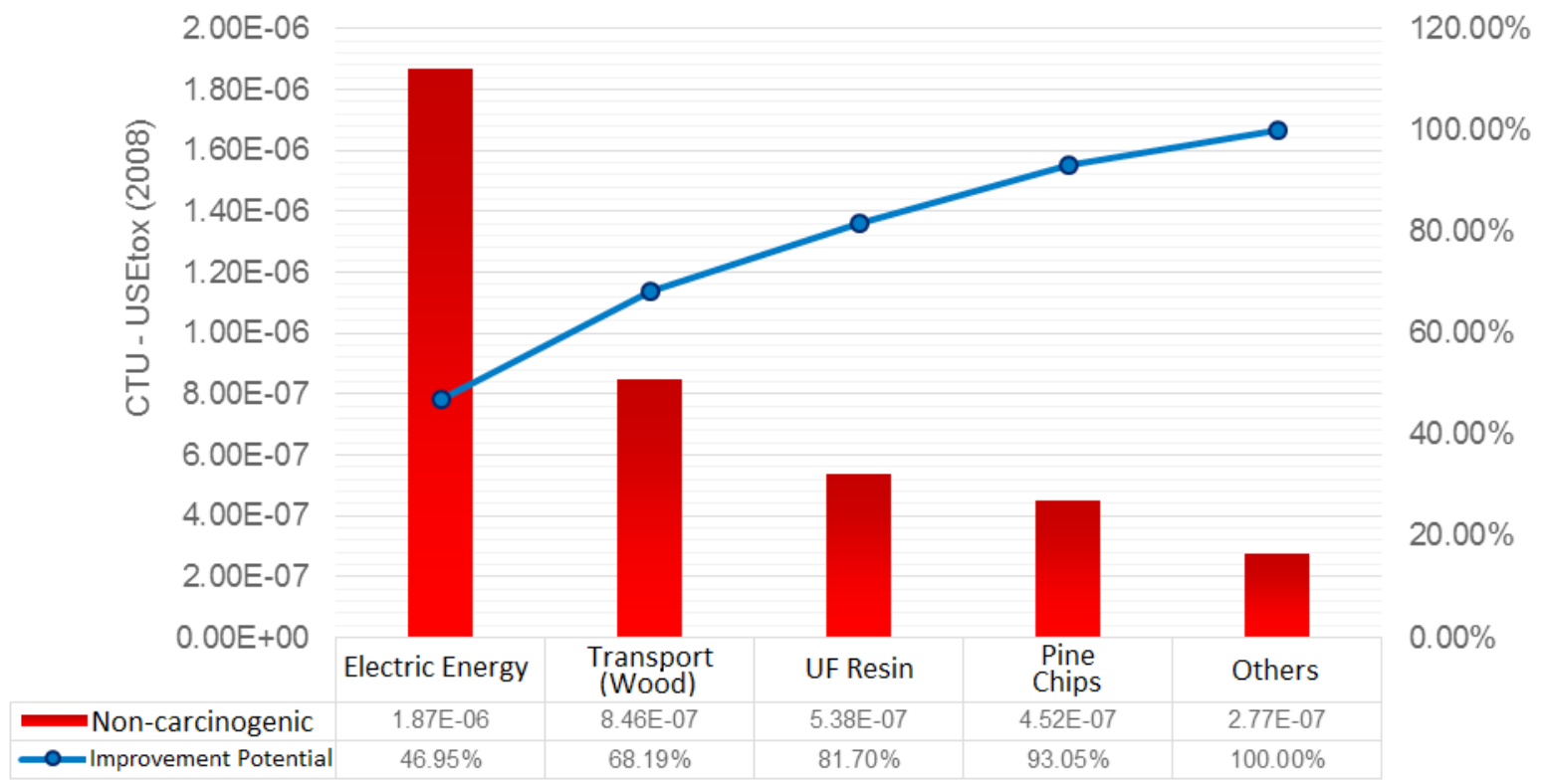

Figure 4 - Pareto chart - non-carcinogenic agents of the human toxicity potential category in the MDF production Source: Piekarski (2013)

As for the impacts of non-carcinogenic kind, the production of electric energy represents $47 \%$ of the impacts, in function of the use of biomass in the energy matrix, which is affected by the toxic substances used, such as herbicides, during the plantation and forest maintenance.

It is possible to observe that the production of electric energy, pine chips and UF resin are present in the HT category as carcinogenic and non-carcinogenic. Taking into account that the same LCIA methods were used in the MDP LCA and that the production processes have similarities, similar results can be observed for both the panels, as shown hereafter.

\subsubsection{MDP Life Cycle Assessment (Silva, 2012)}

The MDP is one of the most consumed wooden panels in the world (Biazus et al., 2010), having a productive numerical data of the particleboard, exceeding 3 million cubical meters per year since 2010 (FAOSTAT, 2015a), and being among the greatest worldwide producers over this market.
Silva (2012) used a cradle to gate approach, considering six stages in the productive system, namely: seedlings production, ground preparation, seedling plantation, forest maintenance, harvest and transport of the wood and industrial production. Beyond the database Ecoinvent, the softwares $\mathrm{GaBi}$ and the PestLCl were used. The CLM (2001), EDIP (1997) and USEtox (2008) methods were used, considering 9 impact categories, wherein only ecotoxicity and human toxicity were covered by the three methods. The USEtox 2008 was considered as the method of reference for the category of human toxicity, which pointed the industrial production subsystem as having 29.1 times more impact to this category than to the forest production subsystem. Therefore, in order to have the Pareto chart construction, only the industrial production subsystem, since the significance of the forest production subsystem is indeed low in relation to the industrial one for this category, as it can be seen in Figure 5 below: 
Brazilian Journal of Operations \& Production Management

Volume 13, Número 1, 2016, pp. 100-109

DOI: 10.14488/BJOPM.2016.v13.n1.a12

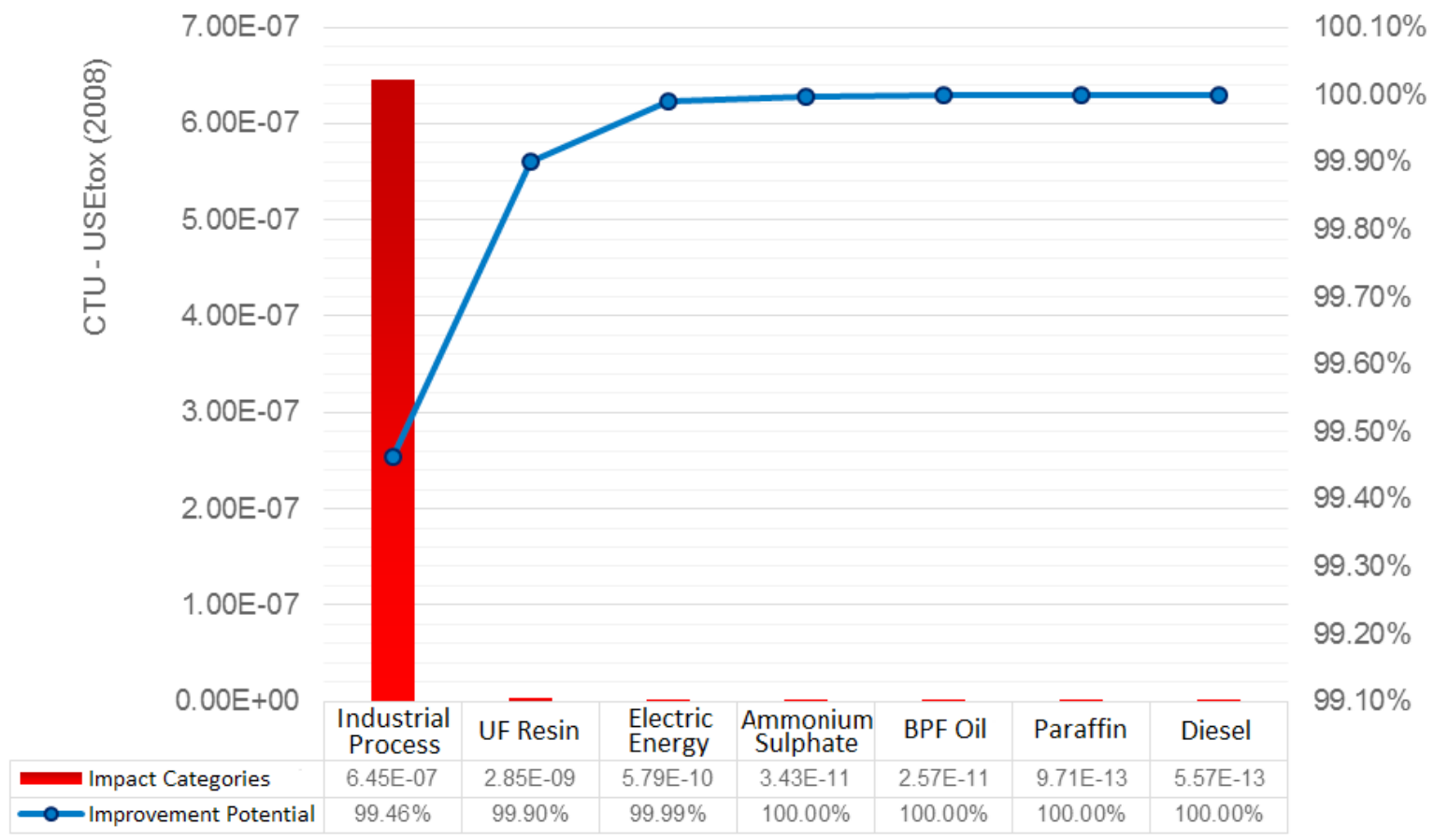

Figure 5 - Pareto chart - carcinogenic agents of the human toxicity potential category in the MDP production

Source: Silva (2012)

Although Silva (2012) does not use the same approach as Piekarski (2013), subdividing the HT category in carcinogenic and non-carcinogenic, it is observed that the global results with regard to the panel productive process are convergent.

Within the industrial production subsystem, the panel production process is responsible for more than $99 \%$ of the impacts due to the free formaldehyde emissions during the process. It is also noticed in an immediate scale, the part of the UF resin production and electric energy, for the same reasons cited in the MDF process.

\subsection{Divergence Among LCIA Methods}

The LCIA methods used in LCA studies are independent and can present differences regarding the results. Each method is, therefore, in a general manner, more indicated for determined categories, as it can be verified in specific literature.

Thus, it is important to highlight that both Piekarski (2013) and Silva (2012) used the same methods for assessment on the impacts, having them been the CML (2001), EDIP (1997) and USEtox (2008). Furthermore, both highlight the occurrence of divergences among the results supplied by the methods regarding the human toxicity category, having them presented different results, indicating different influences over the Human Toxicity category. However, both adopted the USEtox (2008) method as reference for the HT category based on literature recommendations.

\section{SEARCH FOR POTENTIAL IMPROVEMENTS OVER THE WOODEN PANELS ENVIRONMENTAL HANDLING}

Currently, wooden panels have been being used in interiors, for decoration, and in the furniture manufacture. Thus, as already explained, the formaldehyde consumed and emitted during the production, due to the resin used therein shows itself as one of the most responsible for damaging the air quality, affecting comfort, health and productivity. After evidenced the formaldehyde carcinogenic potential (IARC, 2006), studies have been conducted and international bodies have acted to fight the use thereof (Hmatabadi et al., 2012; He et al., 2012).

The industrial process (on-site) is identified as the main cause of the majority of the impacts throughout all the wooden panel life cycle (Piekarski, 2013; Silva, 2012; Benetto et al., 2009). Into it, the main contributors for the HT category within this aspect are: the emitted and present free formaldehyde in the agglutinate agent of the wood; the production of electric energy; and the production of pine chips. 


\subsection{Wooden Panel Production Industrial Process}

At this point, the main contributor for the impacts is the free formaldehyde emission proceeding from the used resin in the process to agglutinate the wood. The panels receive a classification in accordance with the free formaldehyde (HOCH) emission, established by the ABNT NBR 15316-2: 2009 (ABNT, 2009) norms for the MDF and by the ABNT NBR 14810-2: 2013 (ABNT, 2013) to the MDP, as follows:

- E1: Low formaldehyde release: equal or inferior to $8 \mathrm{mg} \mathrm{HOCH} / 100 \mathrm{~g}$ of dry sample;

- E2: Medium formaldehyde release: more than 8 $\mathrm{mg} \mathrm{HOCH} / 100 \mathrm{~g}$ and equal or inferior to $30 \mathrm{mg}$ $\mathrm{HOCH} / 100 \mathrm{~g}$ of dry sample;

In order to establish safe parameters of exposition, there are national and international organizations which regulate these characteristic emissions, such as NR-15, that defines the unhealthy parameters of activities and operations in Brazil, also the Conama (National Environment Council). Further, there are international organizations, such as ACGIH (American Conference of Governmental Industrial Hygienists) and OSHA (Occupational and Safety Health Administration), functioning as auxiliary agents over the solutions conduction and establishment of safe standards for such emissions.

The use of the formaldehyde-based agglutinate, according to Bernardi (2006), has been highly fought by the environment control agencies, since the formaldehyde presents high toxicity level. The OSHA and the IARC claim that there are enough evidences to consider formaldehyde as carcinogenic for human (IARC 2004, IARC, 2006; Shaham et al., 1996), since it can induce the irreparable errors in the DNA reproduction (Friedenson, 2011).

The risks grow as the exposition levels increase. Occupational expositions occur in the formaldehyde-based resin production (NIOSH, 1976) or secondary products since the same ones have innumerable commercial applications (Stayner et al., 1994).

Alternatively, it is possible to conduct alterations in the proportion between formaldehyde and urea, still making possible to confer to the panel the desired physicalmechanical properties. Thus, in accordance with the characteristics of the resin (molar proportion formaldehyde/ urea $(\mathrm{F} / \mathrm{U}))$ used in the panels production process, as well as the mix (whenever it happens) and different pressing characteristics, free formaldehyde emissions different rate occur. However, these alterations significantly affect the wooden panel final properties (Que et al., 2007a).

Panels with E1 classifications are viable to be produced with a lower molar proportion (F/U) than that one used for E2 panels. However, this implies a need for employing a larger amount of resin, so that the panel's properties are maintained, causing alterations in the panel economic aspects and in the characteristic specifications.

\subsection{UF Resin}

Different binding agents can be used in the wooden panels confection, amongst them the phenol-formaldehyde (FF), urea formaldehyde (UF), melamine-urea-formaldehyde (MUF), methyl urea phenol formaldehyde (MUFF), diphenyl methylene polymeric diisocyanate (MDDP) and tanning bark-formaldehyde (TF) resins. However, wide use of the urea-based resin is perceived in the wooden panels manufacture, as it presents lower cost and yet being capable to provide adjusted physical-mechanical properties to the panels (Garcia et al., 2009). Nowadays, the biggest consumption of UF resin takes place in the wooden panels industry (Park et al., 2013), also, the same one is among the most important biding agents (Dunky, 1998). Moreover, UF resin is a common agent for the MDF and MDP production processes.

As shown by the LCA studies, the impacts caused by UF resin occur due to the processes for obtaining urea (Piekarski, 2013; Silva, 2012) and methanol (Piekarski, 2013).

As demonstrated above, there are other binding agents which can be used in the wooden panel production. The substitution of the UF resin for another, such as MUF resin, that in accordance with Silva (2015), presents less impact to the panels production regarding Human Toxicicity, Ecotoxicity and Photochemical Oxidation categories than the UF resin. However, the conduction of more extensive research is necessary, in order to provide more solid results.

\subsection{Electric Energy and Pine Chips}

The contribution of the electric energy generation, as already discussed, occurs by the use of the wood, which ends up having the same pine chips impacts source. Therefore, with regard to the wooden chips used as input material in the panel production process. As a viable solution, SaraviaCortez et al. (2013) indicate the wooden residues use, instead of the wooden chips production from logs. The same the proposal can be used in the process of energy generation through biomass burning.

Through the usage of residues, the same would have already fulfilled part of its life cycle, so the impacts would be minimized, being the environmental load divided as in the allocation process. Iritani et al. (2015) corroborates to the Saravia-Cortez et al. (2013) idea, stressing out that even a small remaining wooden usage portions ratio can result in alteration in the performance. 


\subsection{Transport}

The main mean of transport used across Brazil is the road transport, using vehicles moved by fuels from fossil origin. By the way, these are sources of significant environmental impacts in different categories.

The transport is an indispensable activity to the process and it cannot be extinct, evidently, it is not even viable to be practiced by different transportation means, at least for short distances inland in Brazil. Hence, potentially, viable alternatives would be the reduction of the covered distances, discretion addressed by Iritani et al. (2015), through the substitution of the farthest suppliers.

Another alternative would be the substitution of the diesel engines by biofuel driven transportation. However, it is also noticed the absence of studies that approach such subject. Thus, a detailed analysis would be necessary to confirm the viability of such action.

\section{FINAL CONSIDERATIONS}

Having knowledge about the processes and the practices adopted in the wooden panels' production, potential points of improvement over these systems can be identified, once the materials/processes causing environment impacts are evidenced, and particularly in this case, the impact to the human health they can cause.

In order to conduct a correct assessment of these products, the important usage of an efficient tool and that would be capable to deliver clear results is pointed out. Nowadays, great part of the studies on environment profiles is carried through with the LCA methodology support, as Bocken et al. (2012) affirm, in terms of environmental assessment, this is the most complete and complex tool. The LCA allows the product life cycle to be taken into account completely and it supplies valuable information regarding to its environmental performance guiding improvements toward the reduction of the observed impacts.

LCA is recommended due to its wide usage within the environmental sphere and evidences of its efficiency in research on the wooden panels industry in general (Silva, 2012; Garcia et Freire, 2011). Furthermore, there is a gap in the literature regarding the performance assessment on these panels, mainly in the Brazilian productive scenario.

In addition, the use of natural resources (renewable and non-renewable) and the shortage thereof are subjects discussed increasingly and with a great repercussion and controversy in a worldwide scope. However, with the technological development and the conception of new products and processes, the concern about the consequences of using these products, the real and the potential damages to the environment and society come to light. Therefore, the need for investigating the real effects and inherent environmental impacts related to the production of each of the panels, given their characteristics and the required inputs to their production, is noticed. Hence, a solid picture regarding the risks of each one can be constructed with the intention to guide the establishment of safe production patterns, handling and use thereof, beyond pointing out the best and the most harmful practices.

It is possible to realize that the organizations are already adjusting their practices in order to reduce the impacts of their productive processes, with an increasing natural environment and social conscience growth, clearly linked to the relevant economic aspects.

However, it is noticed that a more rigid regulation by the Brazilian responsible agencies is needed, since, as highlighted by Chipanski (2006), the panels produced in Brazil present a higher formaldehyde emission than the ones of European and American producers.

Still, it is desirable that future studies would cover different categories of the same panel (E1 and E2) inside the Brazilian scenario, in order to consider the local characteristics. This analysis would serve properly to verify the real discrepancies about the potential differences between the inputs and processes used in each thereof, therewith, searching for the application of best practices by the industry, so that it could serve as support to legal requirements in the sector.

\section{ACKNOWLEDGEMENTS}

The authors would like to express their gratitude for the financial support by Federal University of Technology Paraná.

\section{REFERENCES}

Bernardi, R. (2006), Dossiê Técnico: Reconstituição de chapas de aglomerados. SENAI-RS.

Biazus, A, Hora, A. B. and Leite, B. G. P. (2010), "Panorama de mercado: painéis de madeira". BNDES Setorial, Vol.32, pp. 49-90.

Bocken, N. M. P., Allwood, J. M., Willey, A. R. (2012), "Development of a tool for rapidly assessing the implementation difficulty and emissions benefits of innovations", Technovation, Vol. 32, pp.19-31.

Bufalino, L., Corrêa, A. A. R., Sá, V. A., Mendes, L. M., Almeida, N. A., Pizzol, V. D. (2015), "Alternative Compositions of Oriented Strand Boards (OSB) Made With Commercial Woods Produced in Brazil", Ciencia y tecnología, Vol. 17, No.1, pp. 105-116. 
Cabral, C. P. T., Vital, B. R., Lucia, R. M. D., Pimenta, A. S., Soares, C. P. B., Carvalho, A. M. M. L. (2006), "Propriedades de Chapas Tipo OSB, Fabricadas com Partículas Acetiladas de Madeiras de Eucalyptus grandis, Eucalyptus urophylla, Eucalyptus cloeziana e Pinus elliottiil", Revista Árvore, Vol. 30, No.4, pp.659-668.

Demajorovic, J., Silva, A. V. (2010), “Arranjos Produtivos Locais e Práticas de Gestão Sociambiental: uma análise do Pólo Moveleiro de Arapongas", Ambiente \& Sociedade, Vol. 89, No. 1, pp. 131-149.

Dunky, M. (1998), "Urea-formaldehyde (UF) adhesive resins for wood", International Journal of Adhesion \& Adhesives, Vol. 18, pp. 95-107.

Ferreira, J. V. R. (2004), Análise de ciclo de vida dos produtos. Instituto Politécnico de Viseu, 80 p.

Food and Agriculture Organization of the United Nations (FAOSTAT) (2015a). Forestry. Disponível em: < http:// faostat3.fao.org/browse/F/*/E>. (Accessed on: 16 sep. 2015).

Food and Agriculture Organization of the United Nations (FAOSTAT) (2015b). Forest Products Definitions. Disponível em: <http://faostat.fao.org/Portals/_Faostat/documents/ pdf/FAOSTAT-Forestry-def-e.pdf>. (Accessed on 17 sep. 2015).

Freire, A. L. F., Figueirêdo, M. C. B., Rosa, M. F., Araújo Júnior, C. P. (2015), "Impactos ambientais de painéis de madeira e derivados - Uma revisão de literatura", Espacios. Vol. 36, No. 10, pp. 3.

Friedenson, B. (2011), “A common environmental carcinogen unduly affects carriers of cancer mutations", Medical Hypotheses, Vol. 77, No. 5, pp. 791-810.

Garcia, M. P., PICCINI, A. A. P., FERREIRA, E. S. (2014), Avaliação da qualidade de quatro resinas comerciais utilizadas na colagem de painéis de madeira reconstituída. Available at: <http://www2.ufpel.edu.br/cic/2009/cd/pdf/ EN/EN_00299.pdf>. (Accessed on 12 mar 2014).

He, Z., Zhang, Y., Wei, W. (2012), "Formaldehyde and VOC emissions at different manufacturing stages of wood-based panels", Building and Environment, Vol. 47, pp. 197-204.

International Agency for Research on Cancer (IARC), (2006), Monographs on the Evaluation of Carcinogenic Risks to Humans - Volume 88 Formaldehyde, 2-Butoxyethanol and 1-tert-Butoxipran-2-ol. Available at: < http://monographs. iarc.fr/ENG/Monographs/vol88/mono88-6.pdf>. (Accessed on 16 oct. 2015).

International Agency for Research on Cancer (IARC) (2004), IARC CLASSIFIES FORMALDEHYDE AS CARCINOGENIC TO HUMANS. Available at: <http://www.iarc.fr/en/mediacentre/pr/2004/pr153.html>. (Accessed on: 16 oct. 2015).
Iritani, D. R., Silva, D. A. L.; Saavedra, Y. M. B., Grael, P. F. F.; Ometto, A. R. (2015), "Sustainable Strategies analysis through Life Cycle Assessment: a case study in a furniture industry", Journal of Cleaner Production, Vol. 96, pp. 308318.

Leão, M. S., Naveiro, R. M. (2009), "Fatores de competitividade na indústria de móveis de madeira no Brasil", Revista Madeira, Vol. 119, pp. 4-11.

Luz, L. M., Francisco, A. C., Piekarski, C. M. (2015), "Proposed model for assessing the contribution of the indicators obtained from the analysis of life-cycle inventory to the generation of industry innovation", Journal of Cleaner Production, Vol. 96, pp. 339-348.

Molina-Murillo, S. A., Smith, T. M. (2009), “Exploring the use and impact of LCA-based information in corporate communications", The International Journal of Life Cycle Assessment, Vol. 14, No.2, pp.184-194.

Niosh (2015). Criteria for a Recommended Standard of Occupational Exposure for Formaldehyde. Department of Health, Education and Welfare, Washington, DC, 1976, p. 77126. Available at:http://www.cdc.gov/niosh/docs/1970/77126.html. (Accessed on: 16 oct. 2015).

Park, B., Frihart, C. R., Yu, Y., Singh, A. P. (2013), "Hardness evaluation of cured urea-formaldehyde resins with different formaldehyde/urea mole ratios using nanoindentation method", European Polymer Journal, Vol. 49, pp. 3089-3094.

Pehnt, M. (2006), "Dynamic life cycle assessment (LCA) of renewable energy technologies", Renewable Energy, Vol. 31, pp. 55-71.

Piekarski, C. M. (2013), Proposta de melhoria do desempenho ambiental associado ao ciclo de vida da produção de madeira MDF, Dissertação de Mestrado em Engenharia de Produção, Universidade Tecnológica Federal do Paraná, Ponta Grossa, PR.

Piekarski, C. M., Francisco, A. C., Luz, L. M., Alvarenga, T. H. P., Bittencourt, J. V. M. (2014), “Environmental Profile Analysis of MDF Panels Production: Study in a Brazilian Technological Condition. CERNE, Vol. 20, No. 3, pp. 409-418.

Piekarski, C. M., Luz, L. M., Zocche, L., Francisco, A. C. (2013). "Life cycle assessment as entrepreneurial tool for business management and Green innovations", Journal of Technology Management and Innovation., Vol. 8, pp. 44-53.

Que, Z., Furno, T., Katoh, S., Nishino, Y. (2007a), "Effects of urea-formaldehyde resin mole ratio on the properties of particleboard", Building and Environment, Vol. 42, p. 12571263.

Que, Z., Furno, T., Katoh, S., Nishino, Y. (2007b), "Evaluation of three test methods in determination of formaldehyde emission from particleboard bonded with 
different mole ratio in the urea-formaldehyde resin", Building and Environment, Vol. 42, pp. 1242-1249.

Rivela, B., Moreira, M. T., Feijoo, G. (2007), "Life Cycle Inventory of Medium Density Fibreboard", International Journal of Lile Cycle Assessment, Vol. 12, No.3, pp. 143-150.

Rivela, B., Hospido, A., Moreira, M., Feijoo, G. (2006), “Life Cycle Inventory of Particleboard: A Case Study in the Wood Sector", International Journal of Lile Cycle Assessment, Vol. 11, No.2, pp. $106-113$.

Saravia-Cortez, A. M., Herva, M., Garcia-Diéguez, C., ROCA, E. (2013), "Assessing environmental sustainability of particleboard production process by ecological footprint", Journal of Cleaner Production, Vol. 52, p. 301-308.

Silva, D. A. L. (2012), Avaliação do Ciclo de Vida da Produção do Painel MDP no Brasil, Dissertação de Mestrado em Engenharia de Produção, Universidade de São Paulo, São Carlos, SP.

Silva, D. A. L., Lahr, F. A. R., Garcia, R. P., Freira, F. M. C. S., Ometto, A. R. (2013), "Life Cycle Assessment of medium density particleboard (MDP) produced in Brazil", International Journal of Life Cycle Assessment, pp. 14041411.

Silva, D. A. L., Lahr, F. A. L., Varanda, L. D., Christoforo, A. L., Ometto A. R. (2015), "Environmental performance assessment of the melamine-urea-formaldehyde (MUF) resin manufacture: a case study in Brazil, Journal of Cleaner Production, Vol. 96, pp.299-307.

Stayner, L., Ward, E., Petsonk, E. L. (1994), Occupational Medicine: Principles and Practical Applications. Formaldehyde. In Zenz, C. (ed.), Mosby Year Book, St Louis, MO, p. 675-679.

Svoboda, S. (Comp.). Note on Life Cycle Analysis. 1995.

Vidal, A. C. F., Hora, A. B. (2010), Panorama de mercado - painéis de madeira. BNDES Setorial, p. 323384. Available at: < https://web.bndes.gov.br/bib/jspui/ bitstream/1408/3023/4/Panorama\%20de\%20mercado. pdf>. (Accessed on: 13 oct. 2015). 